\title{
Involvement of Striatal Cholinergic Interneurons and M1 and M4 Muscarinic Receptors in Motor Symptoms of Parkinson's Disease
}

\author{
[DSamira Ztaou, ${ }^{1}$ Nicolas Maurice, ${ }^{2}$ Jeremy Camon, ${ }^{1}$ Gaëlle Guiraudie-Capraz, ${ }^{3}$ Lydia Kerkerian-Le Goff, ${ }^{2}$ \\ Corinne Beurrier, ${ }^{2}$ Martine Liberge, ${ }^{1 \star}$ and $๑$ Marianne Amalric ${ }^{1 \star}$ \\ ${ }^{1}$ Aix Marseille University, Centre National de la Recherche Scientifique, LNC, FR3C, 13331 Marseille cdx 03, France, ${ }^{2}$ Aix Marseille University, Centre \\ National de la Recherche Scientifique, IBDM, 13288 Marseille cdx 09, France, and ${ }^{3}$ Aix Marseille University, Centre National de la Recherche Scientifique, \\ NICN, 13344 Marseille cdx 15, France
}

Over the last decade, striatal cholinergic interneurons (ChIs) have reemerged as key actors in the pathophysiology of basal-gangliarelated movement disorders. However, the mechanisms involved are still unclear. In this study, we address the role of ChI activity in the expression of parkinsonian-like motor deficits in a unilateral nigrostriatal 6-hydroxydopamine (6-0HDA) lesion model using optogenetic and pharmacological approaches. Dorsal striatal photoinhibition of ChIs in lesioned ChAT ${ }^{\text {cre/cre }}$ mice expressing halorhodopsin in ChIs reduces akinesia, bradykinesia, and sensorimotor neglect. Muscarinic acetylcholine receptor (mAChR) blockade by scopolamine produces similar anti-parkinsonian effects. To decipher which of the mAChR subtypes provides these beneficial effects, systemic and intrastriatal administration of the selective M1 and M4 mAChR antagonists telenzepine and tropicamide, respectively, were tested in the same model of Parkinson's disease. The two compounds alleviate 6-OHDA lesion-induced motor deficits. Telenzepine produces its beneficial effects by blocking postsynaptic M1 mAChRs expressed on medium spiny neurons (MSNs) at the origin of the indirect striatopallidal and direct striatonigral pathways. The anti-parkinsonian effects of tropicamide were almost completely abolished in mutant lesioned mice that lack M4 mAChRs specifically in dopamine D1-receptor-expressing neurons, suggesting that postsynaptic M4 $\mathrm{mAChRs}$ expressed on direct MSNs mediate the antiakinetic action of tropicamide. The present results show that altered cholinergic transmission via M1 and M4 mAChRs of the dorsal striatum plays a pivotal role in the occurrence of motor symptoms in Parkinson's disease.

Key words: basal ganglia; cholinergic interneurons; motor symptoms; muscarinic receptors; Parkinson's disease; striatum

\section{Significance Statement}

The striatum, where dopaminergic and cholinergic systems interact, is the pivotal structure of basal ganglia involved in pathophysiological changes underlying Parkinson's disease. Here, using optogenetic and pharmacological approaches, we investigated the involvement of striatal cholinergic interneurons (ChIs) and muscarinic receptor subtypes (mAChRs) in the occurrence of a wide range of motor deficits such as akinesia, bradykinesia, motor coordination, and sensorimotor neglect after unilateral nigrostriatal 6-hydroxydopamine lesion in mice. Our results show that photoinhibition of ChIs in the dorsal striatum and pharmacological blockade of muscarinic receptors, specifically postsynaptic M1 and M4 mAChRs, alleviate lesion-induced motor deficits. The present study points to these receptor subtypes as potential targets for the symptomatic treatment of parkinsonian-like motor symptoms.

\section{Introduction}

Parkinson's disease is the most common movement disorder and is associated with akinesia, rigidity, and tremor but also cognitive deficits (Obeso et al., 2000). Neuropathologically, it is defined by a massive degeneration of nigrostriatal dopaminergic neurons. Antimuscarinic drugs were the first widely accepted treatment 
before the discovery of 3,4-dyhydroxy-phenyl-L-alanine (LDOPA), the dopaminergic replacement therapy. They are mainly prescribed to treat tremor (Lees, 2005) and hypertonia, but produce troublesome side effects, including urinary retention, nausea, falls, and cognitive impairment. However, the discovery of drugs acting on specific muscarinic acetylcholine receptor ( $\mathrm{mAChR}$ ) subtypes has raised renewed interest in the modulation of striatal cholinergic signaling to alleviate basal ganglia disorders (Wess et al., 2007; Eskow Jaunarajs et al., 2015; Shen et al., 2015).

Increased excitability of the tonically active striatal cholinergic interneurons (ChIs), which represent $1-2 \%$ of all striatal neurons, may contribute to the dysregulated striatal output pathways in the parkinsonian state because of their dense terminal fields that are primarily directed to the medium spiny neurons (MSNs), which constitute $95 \%$ of the striatal neuronal population (Tepper and Bolam, 2004; Silberberg and Bolam, 2015). Current views of basal ganglia dysfunction suggest that an imbalance between acetylcholine (ACh) and dopamine (DA) activity in the striatum is central to the development of motor symptoms (Di Chiara et al., 1994; Pisani et al., 2007), although recent studies have demonstrated complex and complementary interaction between these two systems upon thalamic stimulation (Threlfell et al., 2012; Parker et al., 2016). In addition, striatal dopaminergic depletion produces profound alterations in the corticostriatal glutamatergic inputs and in GABAergic MSNs (Calabresi et al., 2000; Surmeier et al., 2014; Tritsch and Carter, 2016). The DA D1receptor-expressing MSNs of the direct pathway (D1-MSNs), which project directly to the substantia nigra pars reticulata $(\mathrm{SNr})$ output structure of the basal ganglia, become hypoactive, whereas D2-receptor-expressing MSNs (D2-MSNs) of the indirect pathway, which project to the globus pallidus and then the subthalamic nucleus and the SNr, become functionally hyperactive (Albin et al., 1989). This classical view of basal ganglia functional organization has recently been challenged (Calabresi et al., 2014; Tecuapetla et al., 2014).

ChIs have a wide range of striatal effects through both muscarinic and nicotinic receptors signaling. Muscarinic receptors (mAChRs) are highly expressed within the striatum and primarily on MSNs (Zhou et al., 2003; Kreitzer, 2009). Five distinct G-protein-coupled mAChRs (M1-M5) have been cloned and divided into two main classes according to their pharmacological properties and transduction mechanisms (Wess et al., 2007). The M1 class (M1, M3, and M5) is coupled to Gq/11, whereas the M2 -class (M2 and M4) is coupled to Gi/o proteins. Receptor localization studies have revealed a predominant expression of M1 and M4 mAChRs within the striatum, whereas M2 and M3 mAChRs are clearly less abundant (Zhang et al., 2002; Zhou et al., 2003; Pisani et al., 2007; Langmead et al., 2008; Bonsi et al., 2011) Both types of MSNs possess postsynaptic M1 mAChRs, whereas M4 mAChRs are preferentially expressed postsynaptically on D1MSNs. M4 mAChRs are also found presynaptically on ChIs, where they mediate a negative feedback control on ACh release. The rationale for blocking these receptors selectively in the parkinsonian state deserves to be investigated.

Defining the role of striatal ChIs on motor functions has regained interest using techniques that allow selective ablation of striatal ChIs by diphtheria toxin (Won et al., 2014) or

Correspondence should be addressed to Marianne Amalric, Aix Marseille University, CNRS, UMR 7291, Laboratoire de Neurosciences Cognitives (LNC), FR3C 3512, Case C, 3, place Victor Hugo, 13331 Marseille cedex 03, France. E-mail:marianne.amalric@univ-amu.fr.

DOI:10.1523/JNEUROSCI.0873-16.2016

Copyright $\odot 2016$ the authors $\quad 0270-6474 / 16 / 369162-12 \$ 15.00 / 0$ immunotoxin-mediated cell-targeting techniques (Kaneko et al., 2000; Hikida et al., 2001). Optogenetic modulation of striatal ChIs provides a potent way to decipher ChI functions in the parkinsonian condition in a reversible manner. Here, we used a mice model of Parkinson's disease to investigate the role of ChIs and M1 or M4 mAChRs in the control of motor function.

\section{Materials and Methods}

\section{Animals}

Optogenetics. Choline acetyltransferase (ChAT)-IRES-Cre knock-in mice (ChAT ${ }^{\text {cre/cre }}$ mice, stock number 006410, RRID:IMSR_JAX: 006410) were purchased from Jackson Laboratory.

Pharmacology. Wild-type male C57BL/6 mice (RRID:IMSR_JAX: 000664) 8 weeks of age were purchased from Charles River Laboratories. D1-M4-KO mice were generated as described previously (Jeon et al., 2010). Homozygous floxed M4 female mice were crossed with homozygous floxed M4 male mice that carry the D1-Cre transgene. The resulting mutant mice were then intermated to generate mutant mice that lacked M4 mAChRs only in D1-receptor-expressing neurons (M4 fl/fl D1-Cre mice; referred to as D1-M4-KO mice). This mating scheme also yielded floxed M4 mAChRs mice lacking the D1-Cre transgene. These mice were used as control animals throughout the experiments ( $\mathrm{M} 4 \mathrm{fl} / \mathrm{fl}$ mice; also referred to as control littermates).

Mice were housed in groups of $4-5$ with food and water ad libitum in a temperature-controlled room $\left(24^{\circ} \mathrm{C}\right)$ on a $12: 12 \mathrm{~h}$ dark/light cycle (lights on at 07:00). All procedures were approved by the French National Ethical Committee (authorization no. 00196.01) and in accordance with the recommendations of the EEC (2010/63/UE) for the care and use of laboratory animals.

\section{Genotyping}

Genotyping were performed by PCR analysis of mouse tail genomic DNA using the following primers: forward, $5^{\prime}$-CCTGGAAAATGCTTCTG TCCG-3' and reverse, 5'-CAGGGTGTTATAAGCAATCCC-3'. After an activation step of $10 \mathrm{~min}$ at $94^{\circ} \mathrm{C}$, the amplification reactions were performed for 32 cycles of $30 \mathrm{~s}$ at $94^{\circ} \mathrm{C}, 30 \mathrm{~s}$ at $60^{\circ} \mathrm{C}$, and $45 \mathrm{~s}$ at $72^{\circ} \mathrm{C}$, followed by an additional step at $72^{\circ} \mathrm{C}$ for $7 \mathrm{~min}$. PCRs were run on an iCycler Thermal Cycler apparatus (Bio-Rad) and PCR products were visualized by electrophoresis in $2 \%$ agarose gels. The amplicons were visualized with ethidium bromide by digital scanning with the Bio-Vision image acquisition system (Vilber-Lourmat).

\section{Stereotaxic surgery}

Mice were anesthetized with intraperitoneal injections of ketamine and xylazine (100 and $10 \mathrm{mg} / \mathrm{kg}$, respectively) and mounted on a stereotaxic apparatus (Kopf Instruments). Injections were made with a $10 \mu \mathrm{l} \mathrm{Ham}-$ ilton microsyringe connected to the injector ( 33 gauge; Plastics One) by a polyethylene tubing (Tygon catheter; $0.25 \mathrm{~mm}$ internal diameter) and controlled by an injection pump (CMA/100; CMA/Microdialysis) at the flow of $0.3 \mu \mathrm{l} / \mathrm{min}$. At the end of the injection, injector needles were left in place for 3 more minutes to allow the diffusion of solutions.

Viral expression of opsins in ChIs. Adeno-associated virus (AAV) vector containing opsin transgenes (eNpHR: pAAV-Efla-DIO-eNpHR3.0EYFP) was provided by Dr. Deisseroth (Stanford University) and modified by switching EYFP by TagRFP. The recombinant AAV vector was serotyped with AAV5 coat proteins and packaged by the viral vector core at the University of North Carolina. eNpHR-RFP or RFP was expressed in ChAT-expressing neurons by injecting a Cre-dependent AAV carrying the opsin (i.e., eNpHR-RFP mice) or the reporter gene (control RFP mice) into the dorsal striatum of ChAT ${ }^{\text {cre/cre }}$ mice. The AAV $(1 \mu \mathrm{l})$ was injected unilaterally at 2 dorsoventral sites in the dorsal striatum of $\mathrm{ChAT}^{\text {cre/cre }}$ mice (+1.0 $\mathrm{mm} \mathrm{AP}, \pm 1.5 \mathrm{~mm} \mathrm{ML},-3.4$ and $-3.0 \mathrm{~mm} \mathrm{DV}$; stereotaxic mouse atlas of Paxinos and Franklin, 2001).

6-OHDA lesions. Mice received one unilateral injection $(1.5 \mu \mathrm{l})$ of 6-hydroxydopamine hydrochloride $(2.7 \mu \mathrm{g} / \mu \mathrm{l}$ diluted in $0.9 \%$ sterile $\mathrm{NaCl}$ containing $0.2 \%$ ascorbic acid; Tocris Bioscience) or vehicle $(0.9 \%$ $\mathrm{NaCl}$ in $0.2 \%$ ascorbic acid) into the substantia nigra pars compacta $(\mathrm{SNc})$ at the following coordinates: $-3.0 \mathrm{~mm} \mathrm{AP}, \pm 1.3 \mathrm{~mm} \mathrm{ML},-4.5$ mm DV. 6-OHDA or vehicle injection was done on the side of the intra- 
striatal viral injection in the same surgical session. All experiments were performed at least 2 weeks later and the extent of DA lesion was assessed systematically by anti-tyrosine hydroxylase immunochemistry.

Optic fiber implantation. For optogenetic experiments, mice were implanted with optical fibers consisting of a zirconia ferrule with a $200 \mu \mathrm{m}$ diameter and 3.0-mm-long cleaved bare optic fibers ( 0.22 numerical aperture; Doric Lenses). Fibers were implanted in the striatum ipsilateral to the lesion side at the following coordinates: $+1.0 \mathrm{~mm} \mathrm{AP}, \pm 1.5 \mathrm{~mm}$ ML, $-2.8 \mathrm{~mm}$ DV.

Cannula implantation. For intrastriatal injections, mice were implanted with guide cannula (cut $2.5 \mathrm{~mm}$ below pedestal, 26 gauge; Plastics One) ipsilaterally to the lesioned side at the following coordinates: $+1.0 \mathrm{~mm} \mathrm{AP}, \pm$ $1.5 \mathrm{~mm} \mathrm{ML},-2.5 \mathrm{~mm}$ DV.

\section{Optogenetic photoinhibition}

Light was provided by a yellow laser $(589 \mathrm{~nm}, 75.2 \mathrm{~mW}$, continuous stimulation; Combined Dual Wavelength DPSS Laser System, Laserglow). Optical-fiber light power was measured using a light sensor and intensity calculated using the model based on direct measurements in mammalian brain tissue for predicting irradiance values developed in K. Deisseroth's laboratory. Light intensity at $0.2 \mathrm{~mm}$ from fiber tip was calculated to be $20 \mathrm{~mW} / \mathrm{mm}^{2}$ for yellow light (corresponding to $140 \mathrm{~mW} / \mathrm{mm}^{2}$ at the fiber tip). The duration of optogenetic photoinhibition was dependent on each behavioral testing period (from few seconds to $5 \mathrm{~min}$ ).

\section{In vivo recordings in anesthetized mice}

eNpHR-RFP mice were anesthetized with a mixture of ketamine and xylazine (100 and $10 \mathrm{mg} / \mathrm{kg}$, i.p., respectively, supplemented as needed by intraperitonal injection during the course of the experiment) and fixed in a stereotaxic head frame (Horsley-Clarke apparatus; Unimécanique). Body temperature was monitored by a rectal thermometer and maintained at $36.5^{\circ} \mathrm{C}$ with a homeothermic blanket (Harvard Apparatus). Single-unit activity of striatal cells was recorded extracellularly using glass micropipettes $(25-35 \mathrm{M} \Omega$ ) filled with a $0.5 \mathrm{~m}$ sodium chloride solution containing $1.5 \%$ neurobiotin (Vector Laboratories). Single neuron action potentials were recorded using the active bridge mode of an Axoclamp-2B amplifier (Molecular Devices), amplified, and filtered with an AC/DC amplifier (DAM 50; World Precision Instruments). Data were sampled online at a $10 \mathrm{kHz}$ rate on a computer connected to a CED 1401 interface and analyzed offline using Spike 2 (Cambridge Electronic Design). An optical fiber (core $200 \mu \mathrm{m}$, numerical aperture 0.22; Doric Lenses) was secured $800 \mu \mathrm{m}$ from the tip of the glass micropipette using dental cement and this custom optoprobe was lowered in the striatum ( $+1.0 \mathrm{~mm} \mathrm{AP}, \pm 1.5 \mathrm{~mm}$ ML according to Paxinos and Franklin, 2001). Yellow light was delivered (power at the tip of optical fiber: $140 \mathrm{~mW} / \mathrm{mm}^{2}$ ) using a yellow DPSS Laser $(589 \mathrm{~nm}, 75.2 \mathrm{~mW}$; Changchun New Industries Optoelectronics).

\section{Drug treatment}

Scopolamine hydrobromide $(1.0 \mathrm{mg} / \mathrm{kg})$ and L-DOPA methyl ester $(3.0$ $\mathrm{mg} / \mathrm{kg}$ ) combined with the peripheral DOPA decarboxylase inhibitor benserazide hydrochloride $(12 \mathrm{mg} / \mathrm{kg})$, telenzepine dihydrochloride hydrate $(0.3$ or $3.0 \mathrm{mg} / \mathrm{kg})$, and tropicamide $(2.5$ or $10 \mathrm{mg} / \mathrm{kg}$ ) were dissolved with $0.9 \%$ sterile $\mathrm{NaCl}$ immediately before use. The drugs were injected intraperitoneally at a volume of $10 \mathrm{ml} / \mathrm{kg}$ body weight, $30 \mathrm{~min}$ before behavioral tests to cover the period of maximal drug effect (Aliane et al., 2011; Francardo et al., 2011). All drugs were purchased from Sigma-Aldrich. For intrastriatal injections, awake mice received unilateral injections of telenzepine $(0.75 \mu \mathrm{g}$ or $7.5 \mu \mathrm{g})$ or tropicamide $(0.1,1.0$ or $6.0 \mu \mathrm{g}$ ) diluted in a volume of $0.5 \mu \mathrm{l}$ in $0.9 \%$ sterile $\mathrm{NaCl}$. Local injections were performed with stainless-steel injector needles (cut 3.2 $\mathrm{mm}$ below pedestal, 33 gauge; Plastics One) inserted through the guide cannula previously implanted and fitted so that they protruded $0.7 \mathrm{~mm}$ below into the dorsal striatum. The injectors were connected via a polyethylene catheter to a $10 \mu \mathrm{l}$ microsyringe fitted to a micropump. The flow delivered by the pump was set at $0.25 \mu \mathrm{l} / \mathrm{min}$. Local injections were performed a few minutes before testing.

\section{Behavioral tests}

Pole test. To evaluate bradykinesia induced by 6-OHDA lesion, mice were placed head-upward on the top of a vertical, rough-surfaced pole $(50 \mathrm{~cm}$ height, $1 \mathrm{~cm}$ diameter). Mice were trained to turn to orient downward and descend the pole in two sessions on consecutive days before 6-OHDA lesion. The total time to descend the pole from the time that the animal was placed on the pole until it reached the base of the pole was monitored. Two trials were performed and the best descent time was taken across the trials.

Cylinder test. Mice were placed into a Plexiglas cylinder $(20 \mathrm{~cm}$ height, $9 \mathrm{~cm}$ diameter) to evaluate akinesia and motor asymmetry induced by 6-OHDA lesion. The forelimb asymmetry was assessed by scoring during 5 min weight-bearing contacts on the cylinder wall of the ipsilateral and contralateral paw relative to the lesioned hemisphere, as well as movements made by both paws. Mice failing to reach 10 contacts were excluded from the analyses. Data are expressed as a percentage of ipsilateral and contralateral touches relative to the total number of touches.

Cross maze. To evaluate exploratory behavior and sensorimotor neglect induced by 6-OHDA lesion, mice were placed into a cross maze consisting of 4 identical arms $(45 \times 7 \times 15 \mathrm{~cm})$ at $90^{\circ}$ to each other and made with clear Plexiglas. The acquisition started with the mouse placed in the middle facing one arm. The number of ipsilateral and contralateral turns and the number of times the mouse went straight was monitored for $5 \mathrm{~min}$. Mice failing to reach 10 entries were excluded from the analyses. Data are expressed as a percentage of ipsilateral, contralateral, and straight arm exploration relative to the total number of arm explorations.

Amphetamine-induced rotations. Rotational asymmetry was assessed using Plexiglas bowls ( $8 \mathrm{~cm}$ height, $9 \mathrm{~cm}$ diameter). During testing, mice were video recorded and full turns were counted in the ipsilateral and contralateral directions for $40 \mathrm{~min}$ after the injection of D-amphetamine sulfate $(5 \mathrm{mg} / \mathrm{kg}$, i.p., dissolved in $0.9 \% \mathrm{NaCl}$ at a volume of $10 \mathrm{ml} / \mathrm{kg}$ ). Data are expressed as percentage of ipsilateral rotations toward the side of the lesion relative to the total number of rotations over the $40 \mathrm{~min}$ of testing.

Open field. Mice were individually transferred from the home cage to an open-field arena $(50 \times 50 \mathrm{~cm}$ with a $30 \mathrm{~cm}$-high white plastic wall) virtually divided into peripheral, intermediate, and central zones. The test started by placing the animal in the center of the open field illuminated by a dim light (5 Lux). Each mouse was allowed to explore the open field for $30 \mathrm{~min}$ and its behavior was recorded by a video camera. The distance traveled and the time spent in the different zones was analyzed by a video-tracking software (Viewpoint Life Sciences). In this test, the preferential exploration of the peripheral zone of the open field is considered an index of anxiety.

\section{Experimental design}

Optogenetic experiments. One week before surgery, 28 mice were tested in the pole, cylinder, and cross maze behavioral tests during the same session (prelesion). After 6-OHDA lesion and eNpHR or reporter gene (RFP) injection, mice were divided into two groups: control RFP 6-OHDA $(n=14)$ and eNpHR-RFP 6-OHDA $(n=14)$. After 2 weeks of recovery from surgery, the same behavioral tests were conducted in the two groups with and without optogenetic photoinhibition (postlesion $\mathrm{ON}$ and OFF) in a counterbalanced manner.

Pharmacological experiments. For systemic treatments, sham ( $n=5-8$ per group) and 6-OHDA ( $n=10-14$ per group) mice received scopolamine, L-DOPA, telenzepine, or tropicamide intraperitoneally. Each group (sham and 6-OHDA) was divided into three different subgroups receiving three injections of a given drug (vehicle, dose 1 and dose 2), except for the scopolamine and L-DOPA groups, which received two injections (vehicle, dose 1) in a different order of injection following a Latin-square design over postlesion days 14-22. Between postlesion days 25 and 45, each group (sham and 6-OHDA) received vehicle and telenzepine or tropicamide at the lowest efficient dose and were then tested twice on D-amphetamine-induced circling with a $15 \mathrm{~d}$ washout period in between.

For local treatments, sham ( $n=6-7$ per group) and 6-OHDA $(n=9$ per group) mice, treated either with telenzepine or tropicamide, were divided into 3 different subgroups receiving 3 intrastriatal injections 
A
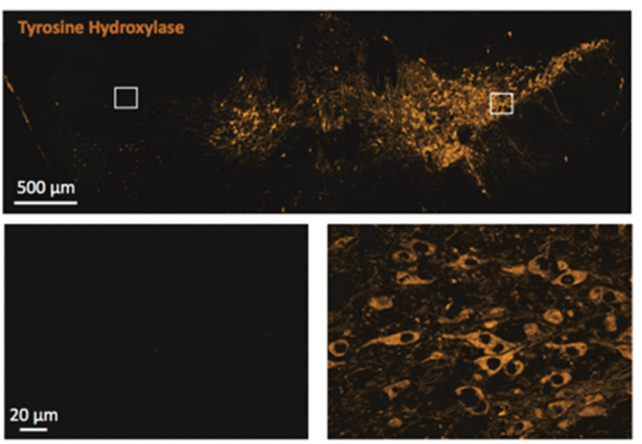

C

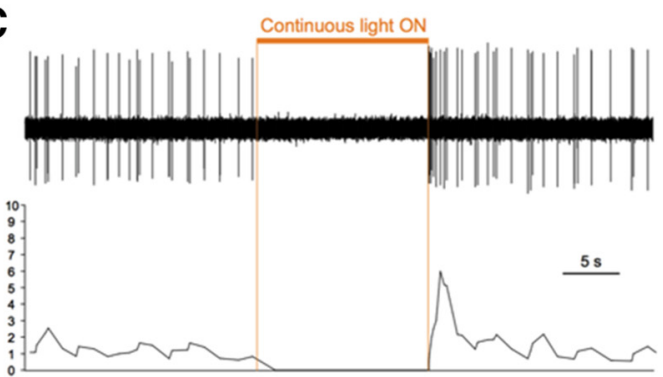

E

\section{Pole}

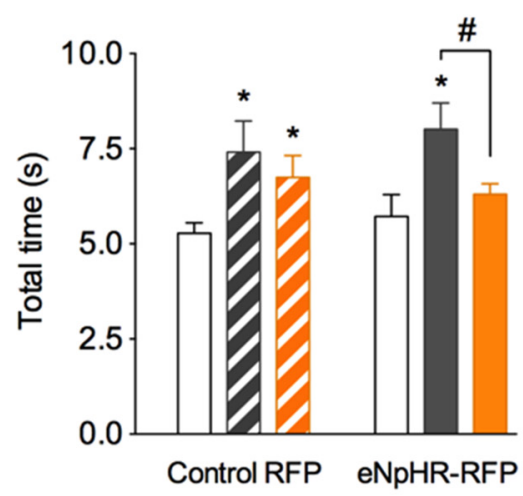

G

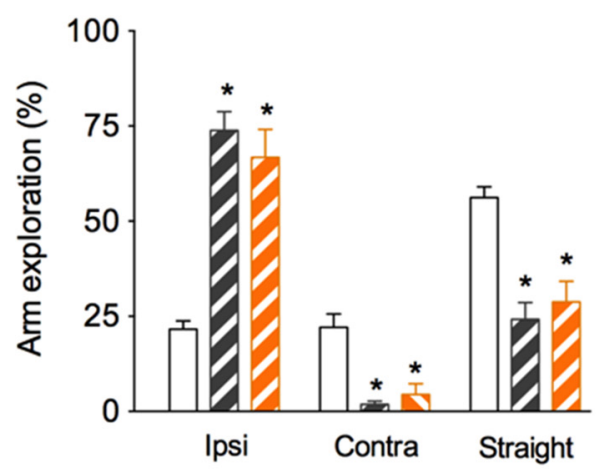

B
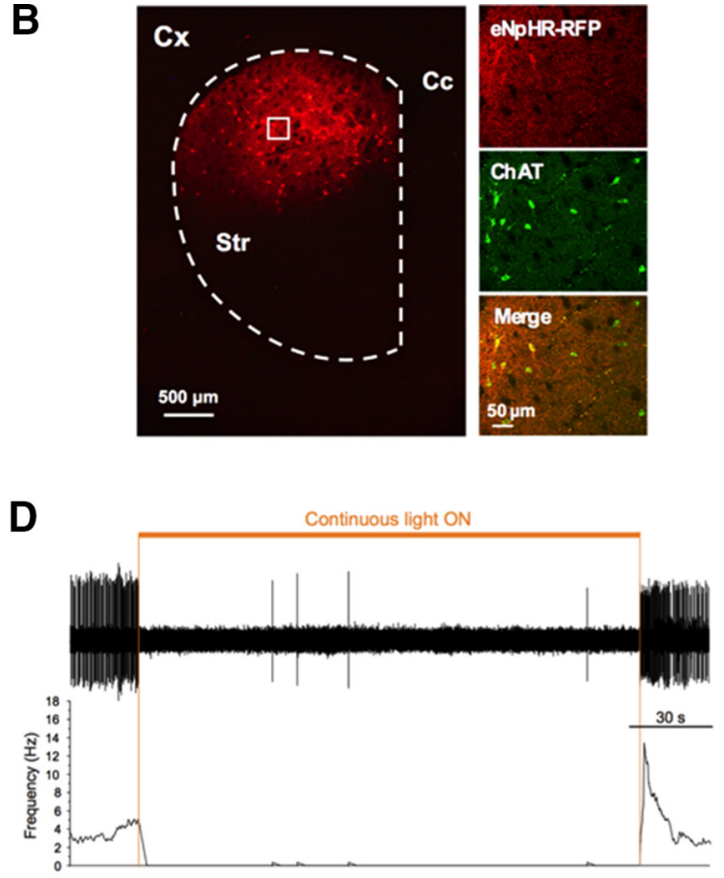

$\mathbf{F}$

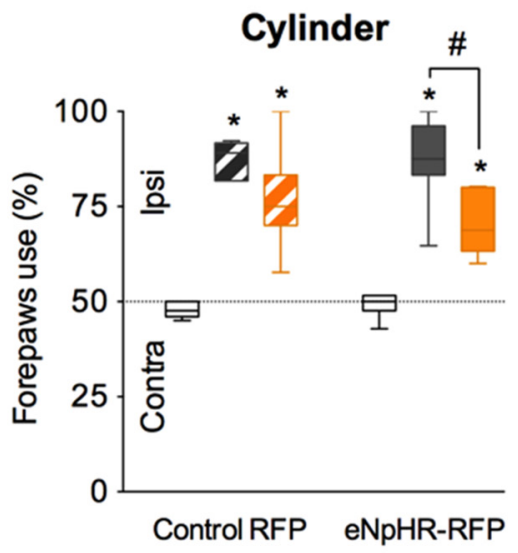

H

Cross maze

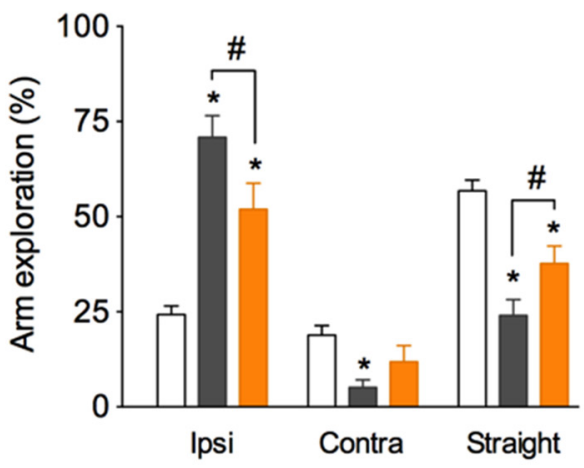

\section{Pre-lesion Control RFP 6-OHDA : $\square$ OFF $\square$ ON \\ eNpHR-RFP 6-OHDA : $\square$ OFF $\square$ ON}

Figure 1. Optogenetic inhibition of striatal Chls reduces motor dysfunction in DA-depleted mice. $A$, Top, Tyrosine hydroxylase immunolabeling in the SNc after unilateral 6-0HDA injection showing near-complete loss of dopaminergic neurons compared with the nonlesioned side. Scale bar, $500 \mu \mathrm{m}$. Bottom, Enlargement of the indicated squares. Scale bar, $20 \mu \mathrm{m}$. $\boldsymbol{B}$, Left: $\mathrm{specific}$ expression of halorhodopsin (eNpHR-RFP) in Chls in the dorsal striatum. C $X$, Cortex; CC, corpus callosum. Right, Coexpression of eNpHR-RFP- and ChAT-expressing neurons in eNpHR-RFP-injected mice. Scale bars, $500 \mu \mathrm{m}$ (left) and $50 \mu \mathrm{m}$ (right). C, D, Top, Raw trace of two isolated units, identified as Chls, inhibited by yellow light continuous stimulation applied for $15 \mathrm{~s}$ and for 3 min. Bottom, Average of the firing rate over time for each unit. $\boldsymbol{E}$, Total descent time in the pole test in control RFP $(n=14)$ and eNpHR-RFP $(n=14)$ mice. $\boldsymbol{F}$, Postural (Figure legend continues.) 
(vehicle, dose 1, and dose 2) over postlesion days 14-22. As for systemic treatments, the order of local injections was designed using a Latinsquare design.

For D1-M4-KO experiments, 37 mice divided into control (M4 $\mathrm{fl} / \mathrm{fl}, n=23)$ and D1-M4 KO $(n=14)$ groups were tested. Before 6-OHDA lesion, control and D1-M4-KO mice were first tested in the open field. After 2 weeks of recovery from surgery, each subgroup (control sham, $n=12$; control 6-OHDA, $n=11$; D1-M4-KO sham, $n=6$; D1-M4-KO 6-OHDA, $n=8)$ received three intrastriatal injections (vehicle and tropicamide dose 1 and dose 2) in a different order following a Latin-square design over postlesion days 14-22.

All injections (systemic or intrastriatal) were performed once every $4 \mathrm{~d}$ and mice were tested in the cylinder and cross maze tests consecutively in the same session.

\section{Histology, immunohistochemistry and microscopy}

Opsin striatal expression and lesion verification. Animals were deeply anesthetized with pentobarbital $(100 \mathrm{mg} / \mathrm{kg})$ and then transcardially perfused with an ice-cold solution of paraformaldehyde $4 \%$ in PBS. After dissection, brains were postfixed overnight in the same fixative at $4^{\circ} \mathrm{C}$, cryoprotected in $30 \%$ sucrose dissolved in $1 \times$ PBS for an additional $36 \mathrm{~h}$ at $4^{\circ} \mathrm{C}$, and frozen. Coronal cryostat sections $(40 \mu \mathrm{m})$ covering the anteroposterior extent of the striatum were used for labeling. Brain sections were permeabilized in PBS with $0.4 \%$ Triton X-100 (PBST) for 30 min at room temperature. Sections were then incubated in a blocking solution composed of PBST with $3 \%$ bovine serum albumin and $10 \%$ normal goat serum for $1 \mathrm{~h}$ at room temperature. For primary antibody exposure, brain sections were incubated overnight at $4^{\circ} \mathrm{C}$ in rabbit anti-RFP (1/ 1000, tebu-bio, 600-401-379) and goat anti-ChAT (1/100, Millipore, $\mathrm{AB} 144 \mathrm{P})$ for colocalization experiments and in mouse anti-tyrosine hydroxylase (1/1000, Millipore, MAB318, AB144P RRID:AB_2079751) to control DA lesion. Sections were then incubated, respectively, in Alexa Fluor 555 donkey anti-rabbit (1/500, Invitrogen, A31572; Thermo Fisher Scientific, A-31572 RRID:AB_2536182), Alexa Fluor 488 donkey antigoat (1/500, Invitrogen, A11055; Thermo Fisher Scientific, A-11055 RRID:AB_2534102), and Alexa Fluor 555 donkey anti mouse (1/500, Invitrogen, A31570; Thermo Fisher Scientific, A-31570 RRID:AB_25 36180) for $1 \mathrm{~h}$ and $30 \mathrm{~min}$ at room temperature. Immunostaining was done on free-floating sections, which were then mounted onto SuperFrost Plus glass slides (VWR) and coverslipped with FluorSave mounting medium (Merck Chemicals). Quantification of colocalization was performed from approximately bregma +1.42 to $+0.02 \mathrm{~mm}$ ( $\sim 14$ sections per mouse) using the Mercator System (Explora Nova) combined with a DMR Leica microscope coupled to a DXC-990P color video camera (Sony). Images were collected using Axio Imager $\mathrm{Zl}$ with the Apotome system (Zeiss) with a Plan-Apochromat $20 \times / 0.8$ or a Plan-Neofluar $\times 40$ / 1.3 objective (Zeiss) for the high magnification or with a Plan-Apochromat $10 \times / 0.45$ objective to acquire whole-brain images.

Control of cannula and optic fiber implantation. Cresyl violet staining of sections was used to locate the trace of cannula implantation and to confirm the accuracy of injection sites and correct optic fiber placement.

\section{Statistical analysis}

All behavioral analyses were conducted on littermates and the values are presented as mean \pm SEM. The effects of 6-OHDA lesion, optogenetic photoinhibition, or pharmacological treatments on behavioral performances of the different groups were tested by means of repeatedmeasures one-way or two-way ANOVA, followed by adapted post hoc tests between groups (Bonferroni's or Tukey's multiple-comparisons test). For the locomotor activity (open field), data were analyzed using unpaired Student's $t$ test. Values of $p<0.05$ were considered significant

$\leftarrow$

(Figure legend continued.) asymmetry in the cylinder in control RFP $(n=7)$ and eNpHR-RFP $(n=7)$ mice. $\mathbf{G}, \boldsymbol{H}$, Arm exploration (ipsilateral, contralateral, and straight arm exploration) in the cross maze in control RFP $(n=14)$ and eNpHR-RFP $(n=14)$ mice. Behavioral tests were performed under three conditions: prelesion, 6-OHDA laser OFF, and 6-OHDA laser ON. Data are reported as mean \pm SEM. Tukey's test after significant one-way repeated-measures ANOVA: ${ }^{*} p<0.05$ versus prelesion condition; $\# p<0.05$, laser $0 \mathrm{~N}$ versus laser $0 \mathrm{FF}$. for all analyses. Statistical analyses were performed using Prism 6 software (GraphPad).

\section{Results}

\section{Photoinhibition of striatal ChI activity alleviates parkinsonian-like motor symptoms}

We examined the impact of optogenetic photoinhibition of striatal ChIs on motor function in parkinsonian conditions. Unilateral 6-OHDA injection into the SNc resulted in a near-complete loss of dopaminergic neurons compared with the nonlesioned side (Fig. 1A). In eNpHR-RFP mice, opsin-expressing neurons were largely confined to the dorsal part of the striatum and were identified as ChAT-expressing neurons (Fig. 1B).

In vivo electrophysiological recordings of ChIs in anesthetized nonlesioned eNpHR-RFP mice were performed to verify the impact on their electrophysiological activity of eNpHR photostimulation applied continuously for $15 \mathrm{~s}$ (Fig. 1C) and $3 \mathrm{~min}$ (Fig. 1D). Yellow light inhibited action potential firing of striatal ChIs during the entire duration of laser illumination in the two conditions.

To evaluate bradykinesia, mice were first tested in the pole test. 6-OHDA mice, either control RFP or eNpHR-RFP, showed a significant increase in the total time to descend the pole compared with prelesion level [Fig. $1 E ; F_{(2,26)}=4.534, p=0.0205$, Tukey's test, $p=0.0067$ (control RFP); $F_{(2,26)}=4.553, p=$ 0.0202 , Tukey's test, $p=0.0075$ (eNpHR-RFP)]. Yellow laser $(589 \mathrm{~nm})$ illumination of striatal ChIs ipsilateral to the lesioned side did not affect the descent time of control RFP 6-OHDA mice (Tukey's test, laser ON versus OFF, $p=0.3631$ ), whereas it significantly reduced the descent time of eNpHR-RFP 6-OHDA mice (Tukey's test, laser ON versus OFF, $p=0.0394$ ).

Unilateral 6-OHDA mice were then tested for forelimb asymmetry using the cylinder test (Fig. $1 F$ ). Before lesion, either control RFP or eNpHR-RFP mice used their two forepaws indifferently during exploratory rearing. The score of forepaws use is close to $50 \%$, showing that nonlesioned mice have no preference between left or right paw use. In contrast, control RFP and eNpHR-RFP 6-OHDA mice significantly used their forepaw ipsilateral to the lesion due to contralateral forelimb akinesia, compared with prelesion $\left[F_{(2,12)}=37.21, p<0.0001\right.$, Tukey's test, $p<0.0001$ (control RFP); $F_{(2,12)}=24.92, p<0.0001$, Tukey's test, $p<0.0001$ (eNpHR-RFP)]. Yellow laser illumination of striatal ChIs showed no significant difference in control RFP $6-\mathrm{OHDA}$ mice (Tukey's test, laser ON versus OFF, $p=0.2630$ ), whereas it produced a significant reduction of the ipsilateral asymmetry in eNpHR-RFP 6-OHDA mice (Tukey's test, laser ON versus OFF, $p=0.0211$ ).

We further tested mice in a novel exploratory cross maze environment (Fig. 1G,H). Before 6-OHDA lesion, the natural tendency of mice is to explore the apparatus mainly by going back and forth into the straight arm $(60 \%$ of the time in prelesion condition), with only a few equivalent turns into the right or left arms (20\%). Unilateral 6-OHDA lesion in the control RFP and eNpHR-RFP groups totally disrupted this strategy by inducing a bias in arm explorations. We observed a significant increase of ipsilateral turns to the lesioned side associated with a decrease of contralateral turns and straight arm exploration, reflecting sensorimotor neglect [Fig. $1 G, H ; F_{(8,104)}=34.3, p<0.0001$, Tukey's test, $p<0.0001, p=0.0018, p<0.0001$ ipsilateral, contralateral, and straight arm exploration, respectively (control RFP); $F_{(8,104)}=24.92, p<0.0001$, Tukey's test, $p<0.0001, p=0.0312$, $p<0.0001$ ipsilateral, contralateral, and straight arm exploration, respectively (eNpHR-RFP)]. Yellow laser illumination of striatal ChIs did not affect exploration in control RFP 6-OHDA 
mice (Fig. 1G; Tukey's test, laser ON versus OFF, $p=0.2636, p=0.6856, p=$ 0.4736 ipsilateral, contralateral, and straight arm exploration, respectively), whereas it significantly decreased ipsilateral arm exploration and increased straight arm exploration in eNpHR-RFP 6-OHDA mice. A tendency to enter the contralateral arm was also observed, but did not reach a significant level (Fig. $1 H$; Tukey's test, laser ON versus OFF, $p=$ $0.0035, p=0.2874, p=0.0328$ ipsilateral, contralateral, and straight arm exploration, respectively).

\section{Muscarinic receptors blockade in unilateral 6-OHDA mice restores motor function}

To investigate which cholinergic receptors are involved in the anti-parkinsonian effects, we tested the blockade of mAChRs with scopolamine, a large-spectrum antagonist. Unilateral 6-OHDA lesion induced a significant increase of the ipsilateral asymmetry in the cylinder test. Scopolamine ( $1 \mathrm{mg} / \mathrm{kg}$, i.p.) significantly reduced the ipsilateral asymmetry of 6-OHDA mice in the cylinder but had no significant effect in the sham group [Fig. $2 A 1 ; F_{(1,20)}=103.7, p<0.0001$, Bonferroni's test, $p>0.9999$ (sham) and $p<$ 0.0001 (6-OHDA)]. Scopolamine, at the same dose of $1 \mathrm{mg} / \mathrm{kg}$ that did not modify exploratory behavior of sham group in the cross maze (Fig. $2 A 2 ; F_{(2,21)}=1.206, p=$ $0.3192)$, significantly modified 6-OHDA mice behavior $\left(F_{(2,39)}=73.99, p<\right.$ $0.0001)$. It also decreased ipsilateral arm exploration and increased straight arm exploration, but did not affect contralateral bias in 6-OHDA mice (Bonferroni's test, $p<0.0001, p=0.8645, p<0.0001$ ipsilateral, contralateral, and straight arm exploration, respectively).

To compare the therapeutic effect of L-DOPA in these assays, an acute injection of L-DOPA was tested in separate groups of 6-OHDA mice. L-DOPA at a dose of $6 \mathrm{mg} / \mathrm{kg}$ induced contralateral rotations and forelimb abnormal involuntary movements (AIMs) in all tested animals $(n=6)$, defined as dyskinesia (data not shown), preventing behavioral assessment in the cylinder and cross maze tests. L-DOPA injected at $3 \mathrm{mg} / \mathrm{kg}$ intraperitoneally in a group of 14 6-OHDA mice produced AIMs in 4 of them, so these mice were excluded from the analysis. In the lesioned mice that did not show dyskinesia, L-DOPA significantly reduced the ipsilateral asymmetry in the cylinder [Fig. $2 B 1 ; F_{(1,15)}=86.02, p<0.0001$, Bonferroni's test, $p>0.9999$ (sham) and $p<0.0001$ (6-OHDA)]. It also decreased ipsilateral arm exploration and increased contralateral and straight arm exploration in the cross maze of 6-OHDA mice $\left(F_{(2,27)}=110.3, p<0.0001\right.$; Bonferroni's test, $p<$ 0.0001, $p<0.0001, p=0.0011$ ipsilateral, contralateral, and straight arm exploration, respectively) but had no effect on the

\section{B - L-DOPA}

\section{B1}

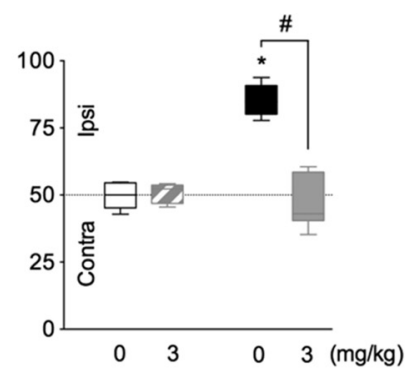

\section{B2}
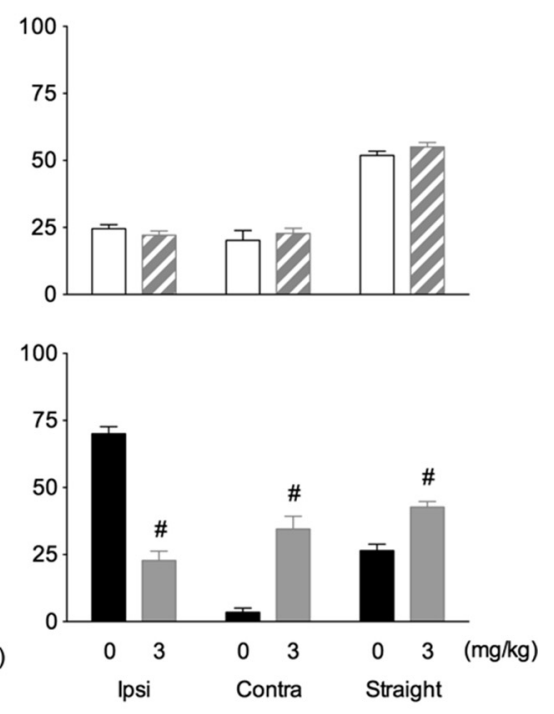

Vehicle-sham

Vehicle-6-OHDA

L-DOPA-sham

Figure 2. Muscarinic receptor blockade and L-DOPA administration restore motor function in DA-depleted mice. $A$, Effects of the nonselective mAChR antagonist scopolamine (1 $\mathrm{mg} / \mathrm{kg}$, i.p.) in the cylinder (A $\mathbf{1})$ and cross maze $(\boldsymbol{A} \boldsymbol{2})$ tests. Each sham $(n=8)$ and $(n=14)$ group received 2 injections (vehicle or scopolamine, $1 \mathrm{mg} / \mathrm{kg}$ ). Values are shown as mean \pm SEM. Bonferroni's test after significant two-way repeated-measures ANOVA: ${ }^{*} p<0.01$ versus vehicle-sham group; $\# p<0.01$ versus vehicle-6Droup. B, Effects of L-DOPA (3 mg/kg, i.p.) in the cylinder (B1) and cross maze (B2) tests. Each sham $(n=7)$ and 6-OHDA $(n=10)$ group received 2 injections (vehicle or L-DOPA $3 \mathrm{mg} / \mathrm{kg}$ ). Values are shown as mean \pm SEM. Bonferroni's test after significant two-way repeated-measures ANOVA: ${ }^{*} p<0.01$ versus vehicle-sham group; $\# p<0.01$ versus vehicle-6-OHDA group.

exploratory behavior of sham group (Fig. $2 B 2 ; F_{(2,18)}=1.059$, $p=0.3676)$.

M1 and M4 mAChRs blockade improves motor functions in unilateral 6-OHDA mice

To determine which muscarinic receptors are involved in these effects, we injected selective M1 and M4 mAChR antagonists (telenzepine and tropicamide, respectively). In this study, doses of mAChR antagonists were selected because of their lack of effect on spontaneous locomotion in nonlesioned animals (data not shown).

The preferential M1 mAChR antagonist telenzepine (0.3 and 3 $\mathrm{mg} / \mathrm{kg}$, i.p.) dose-dependently reduced the ipsilateral asymmetry in 6-OHDA mice in the cylinder but had no significant effect in the sham group [Fig. $3 A 1 ; F_{(2,26)}=8.897, p=0.0011$; Tukey's test, $p=$ $0.9908(0.3 \mathrm{mg} / \mathrm{kg})$ and $p=0.9997(3 \mathrm{mg} / \mathrm{kg})$ for sham; $p=0.0477$ $(0.3 \mathrm{mg} / \mathrm{kg})$ and $p<0.0001(3 \mathrm{mg} / \mathrm{kg})$ for $6-\mathrm{OHDA}]$. Telenzepine 


\section{A - Telenzepine}

\section{A1 Cylinder}

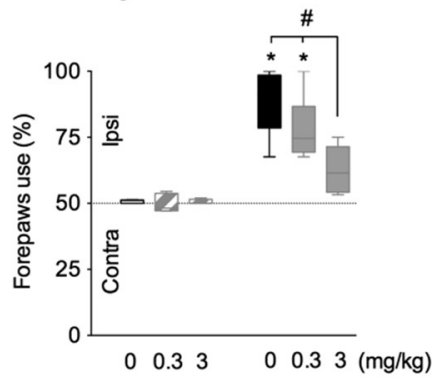

A2 Cross maze
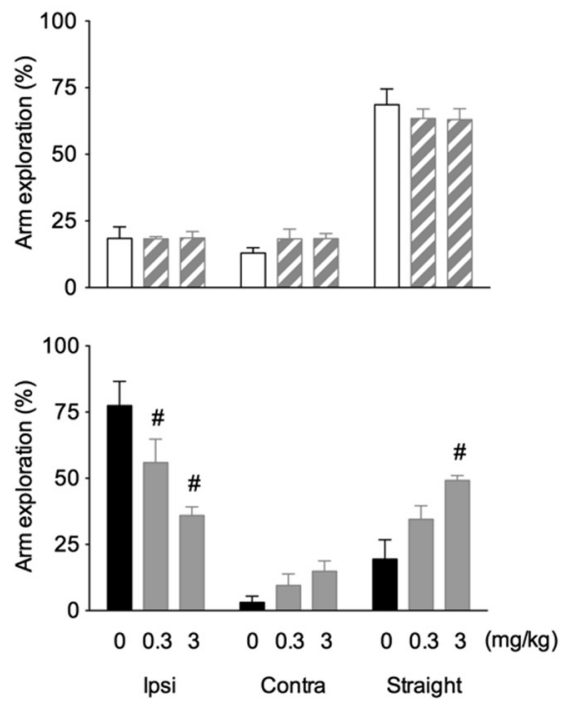

\section{A3 Amphetamine}

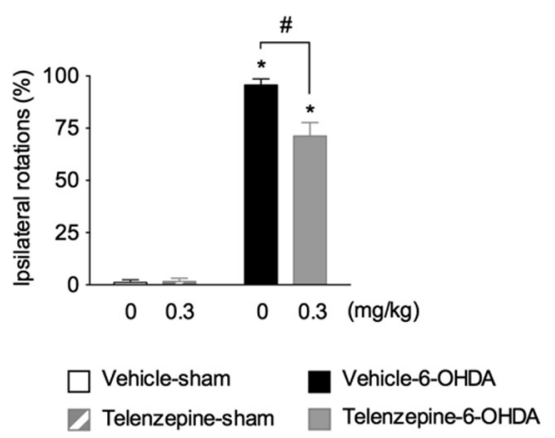

\section{B - Tropicamide}

\section{B1}

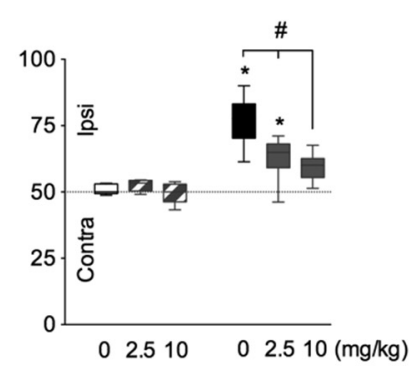

B2
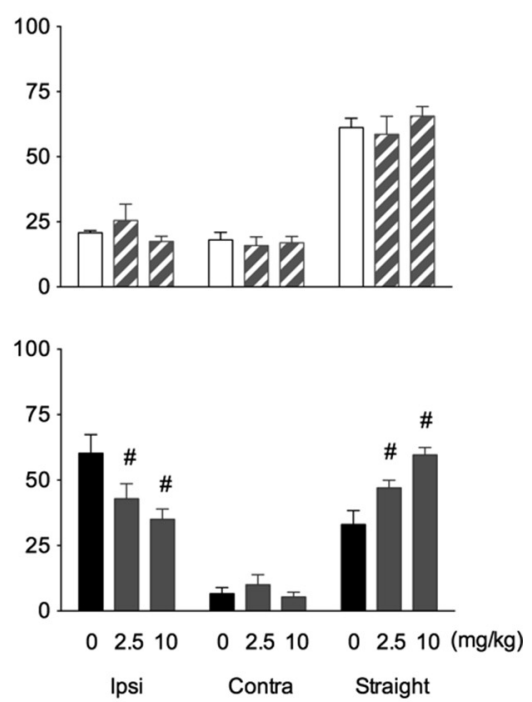

B3

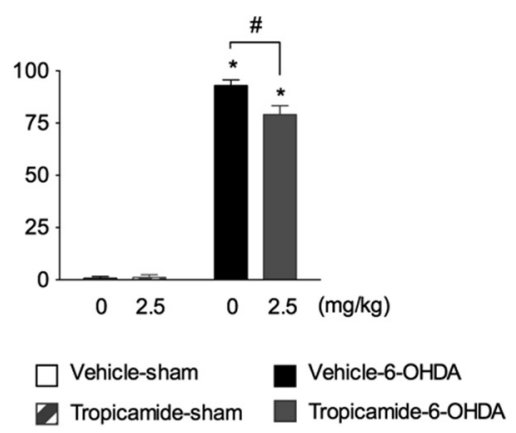

Figure 3. $\mathrm{M} 1$ and $M 4 \mathrm{mAChR}$ blockade improves motor function in DA-depleted mice. $A$, Effects of the selective M1 $\mathrm{mAChR}$ antagonist telenzepine ( 0.3 and $3 \mathrm{mg} / \mathrm{kg}$, i.p.) in the cylinder $(\boldsymbol{A} \boldsymbol{1})$ and cross maze $(\boldsymbol{A} \boldsymbol{2})$ tests. Each sham $(n=5)$ and $6-0 H D A(n=10)$ group received 3 injections (vehicle or telenzepine 0.3 and $3 \mathrm{mg} / \mathrm{kg}$ ). Data are reported as mean \pm SEM. Tukey's test after significant two-way repeated-measures ANOVA: ${ }^{*} p<0.01$ versus vehicle-sham group; $\# p<0.05$ versus vehicle-6-0HDA group. Amphetamine-induced rotational asymmetry (A3) was further tested in each sham $(n=5)$ and $6-0$ HDA ( $n=8$ ) group, which received 2 injections (vehicle or telenzepine $0.3 \mathrm{mg} / \mathrm{kg}$ ) with a $15 \mathrm{~d}$ washout period in between. Values are shown as mean \pm SEM. Bonferroni's test after significant two-way repeated-measures ANOVA: ${ }^{*} p<$ 0.01 versus vehicle-sham group; $\# p<0.01$ versus vehicle-6-OHDA group. $\boldsymbol{B}$, Effects of selective M4 mAChR antagonist tropicamide $(2.5$ and $10 \mathrm{mg} / \mathrm{kg}$, i.p.) in the cylinder (B1) and the cross maze (B2). Each sham $(n=5)$ and 6-OHDA $(n=10)$ group received 3 injections (vehicle or tropicamide 2.5 and $10 \mathrm{mg} / \mathrm{kg}$ ). Data are reported as mean \pm SEM. Tukey's test after significant two-way repeated-measures ANOVA: ${ }^{*} p<0.01$ versus vehicle-sham group; $\# p<0.05$ versus vehicle- $6-0$ HDA group. Amphetamine-induced rotational asymmetry (B3) was further tested in each sham $(n=5)$ and 6-OHDA $(n=8)$ group, which received 2 injections (vehicle or tropicamide $2.5 \mathrm{mg} / \mathrm{kg}$ ). Values are shown as mean \pm SEM. Bonferroni's test after significant two-way repeated-measures ANOVA: ${ }^{*} p<0.01$ versus vehicle-sham group; $\# p<0.01$ versus vehicle-6OHDA group.

had no effect on the sham group in the cross maze [Fig. 3A2; $F_{(4,24)}=1.540, p=0.2224$ ], but significantly decreased ipsilateral bias and increased straight arm exploration in 6-OHDA mice $\left[F_{(4,54)}=17.11, p<0.0001\right.$; Tukey's test, $p=0,0036(0.3 \mathrm{mg} / \mathrm{kg})$ and $p<0,0001(3 \mathrm{mg} / \mathrm{kg})$ for ipsilateral; $p=$ $0.5735(0.3 \mathrm{mg} / \mathrm{kg})$ and $p=0.1641(3 \mathrm{mg} /$ $\mathrm{kg})$ for contralateral; $p=0.0533(0.3 \mathrm{mg} / \mathrm{kg})$ and $p<0.0001(3 \mathrm{mg} / \mathrm{kg})$ for straight arm exploration]. The effects of M1 mAChR blockade were then tested on amphetamine-induced rotational asymmetry. Amphetamine ( $5 \mathrm{mg} / \mathrm{kg}$, i.p.) induced ipsilateral rotations in 6-OHDA mice. Telenzepine at a dose of $0.3 \mathrm{mg} / \mathrm{kg}$ reduced amphetamine-induced rotations over the 40 min test in 6-OHDA mice but had no effect in sham group [Fig. 3A3; $F_{(1,12)}=$ 6.636, $p=0.0243$, Bonferroni's test, $p>$ 0.9999 (sham) and $p=0.0023$ (6-OHDA)].

In 6-OHDA mice, the preferential M4 $\mathrm{mAChR}$ antagonist tropicamide (2.5 and $10 \mathrm{mg} / \mathrm{kg}$, i.p.) dose-dependently reduced the ipsilateral asymmetry in 6-OHDA mice in the cylinder but had no significant effect in sham group [Fig. $3 B 1 ; F_{(2,26)}=$ $7.560, p=0.0026$; Tukey's test, $p=0.9007$ $(2.5 \mathrm{mg} / \mathrm{kg})$ and $p=0.9335(10 \mathrm{mg} / \mathrm{kg})$ for sham; $p<0.0001(2.5 \mathrm{mg} / \mathrm{kg})$ and $p<$ $0.0001(10 \mathrm{mg} / \mathrm{kg})$ for $6-\mathrm{OHDA}]$. Tropicamide had no effect on the sham group in the cross maze (Fig. 3B2; $F_{(4,24)}=1.002$, $p=0.4257]$, whereas it significantly decreased ipsilateral arm exploration and increased straight arm exploration in 6-OHDA mice $\left[F_{(4,54)}=12.38, p<\right.$ 0.0001 ; Tukey's test, $p=0,0052(2.5 \mathrm{mg} /$ $\mathrm{kg})$ and $p<0,0001(10 \mathrm{mg} / \mathrm{kg})$ for ipsilateral; $p=0.7976(2.5 \mathrm{mg} / \mathrm{kg})$ and $p=$ $0.9690(10 \mathrm{mg} / \mathrm{kg})$ for contralateral; $p=$ $0.0292(2.5 \mathrm{mg} / \mathrm{kg})$ and $p<0.0001(10$ $\mathrm{mg} / \mathrm{kg}$ ) for straight arm exploration]. In amphetamine-induced rotational asymmetry, ipsilateral rotations produced by 6-OHDA lesion were reduced by tropicamide at the dose of $2.5 \mathrm{mg} / \mathrm{kg}$, whereas no such effect was observed in the sham group [Fig. 3B3; $F_{(1,12)}=5.026, p=$ 0.0446 , Bonferroni's test, $p>0.9999$ (sham) and $p=0.0067$ (6-OHDA)].

\section{Dorsal striatal M1 and M4 mAChR} blockade is involved in the beneficial effect on parkinsonian-like motor deficits

To investigate the role of M1 and M4 $\mathrm{mAChRs}$ of the striatum in the mediation of these behavioral effects, we injected telenzepine or tropicamide directly into the dorsal part of the striatum (Fig. 4A). Only mice showing the appropriate injection sites were used for data analysis. In- 
trastriatal injection of telenzepine $(0.75$ and $7.5 \mu \mathrm{g}$ ) dose-dependently reduced the ipsilateral asymmetry in the cylinder (Fig. $4 B 1 ; F_{(2,28)}=44.19, p<0.0001$; Tukey's test, $p=0.9783(0.75 \mu \mathrm{g})$ and $p=$ $0.9926(7.5 \mu \mathrm{g})$ for sham; $p<0.0001(0.75$ $\mu \mathrm{g})$ and $p<0.0001(7.5 \mu \mathrm{g})$ for 6-OHDA]. Telenzepine had no effect on sham group in the cross maze (Fig. 4B2; $\left.F_{(4,36)}=2.528, p=0.0574\right)$, whereas it significantly decreased ipsilateral arm exploration and increased straight arm exploration in 6-OHDA mice $\left[F_{(4,48)}=\right.$ 24.75, $p<0.0001$; Tukey's test, $p<0.0001$ $(0.75 \mu \mathrm{g})$ and $p<0,0001(7.5 \mu \mathrm{g})$ for ipsilateral; $p=0.8730(0.75 \mu \mathrm{g})$ and $p=$ $0.5503(7.5 \mu \mathrm{g})$ for contralateral; $p<$ $0.0001(0.75 \mu \mathrm{g})$ and $p<0.0001(7.5 \mu \mathrm{g})$ for straight arm exploration].

Local striatal injection of tropicamide ( 1 and $6 \mu \mathrm{g}$ ) reduced ipsilateral asymmetry significantly in the cylinder in a dose-dependent manner [Fig. 4C1; $F_{(2,26)}=13.14, p=0.0001$; Tukey's test, $p=0.9686(1 \mu \mathrm{g})$ and $p=0.8445(6 \mu \mathrm{g})$ for sham; $p=0.0024(1 \mu \mathrm{g})$ and $p<$ $0.0001(6 \mu \mathrm{g})$ for 6-OHDA]. Tropicamide had no effect on the sham group in the cross maze (Fig. $4 C 2 ; F_{(4,30)}=2.484, p=$ 0.0648 , whereas it significantly reduced ipsilateral arm exploration and increased straight exploration in 6-OHDA mice $\left[F_{(4,48)}=31.47, p<0.0001 ;\right.$ Tukey's test, $p=0.0002(1 \mu \mathrm{g})$ and $p<0,0001(6 \mu \mathrm{g})$ for ipsilateral; $p=0.2470(1 \mu \mathrm{g})$ and $p=$ $0.4087(6 \mu \mathrm{g})$ for contralateral; $p=0.0500$ $(1 \mu \mathrm{g})$ and $p<0.0001(6 \mu \mathrm{g})$ for straight arm exploration)].

\section{Local injection of M4 mAChR} antagonist has no effect on motor deficits induced by unilateral 6-OHDA lesion in transgenic D1-M4-KO mice The effects of M4 mAChR deletion only in D1-receptor-expressing neurons were first evaluated on basal locomotor activity in an open field for 30 min by comparing nonlesioned D1-M4-KO mice and their control littermates (M4 fl/fl mice) (Fig. $5 A$ ). The unpaired $t$ test revealed a trend toward increased global locomotion in D1-M4-KO mice compared with control mice that did not reach a significant level (Fig. 5A; unpaired Student's $t$ test, $t_{(19)}=$ $1.379, p=0.1839)$. The exploratory behavior was evaluated by the time spent in the peripheral, intermediate, and central zones. D1-M4-KO mice spent significantly more time in the central zone than did control mice (Fig. $5 A$; unpaired Student's $t$ test, $\left.t_{(19)}=2.151, p=0.0445\right)$, suggesting an anxiolytic phenotype in these transgenic mice.

In control littermates, local striatal injection of tropicamide at the dose of $1 \mu \mathrm{g}$ reduced significantly the ipsilateral asymmetry in

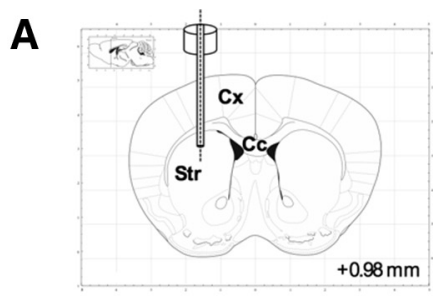

B - Telenzepine

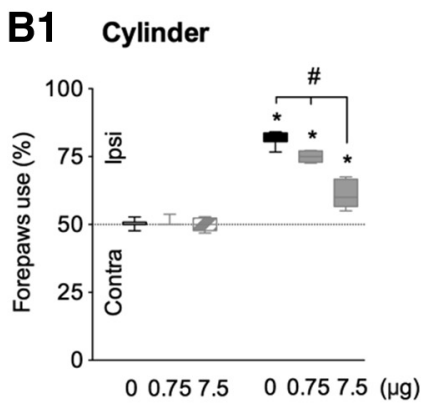

B2 Cross maze
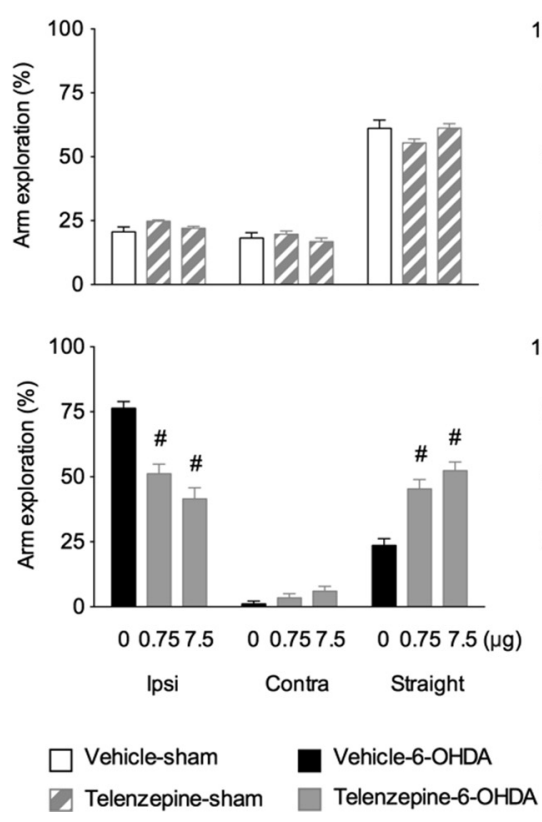

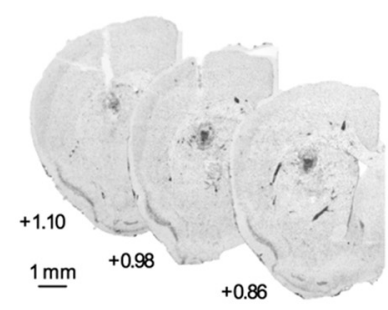

\section{C - Tropicamide}

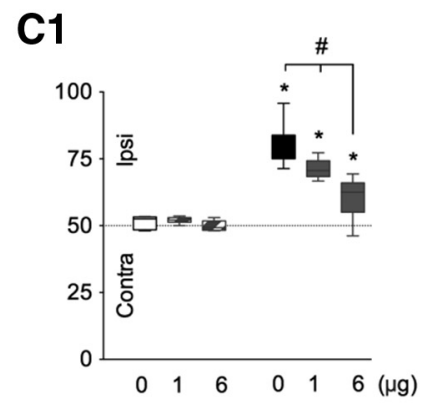

C2
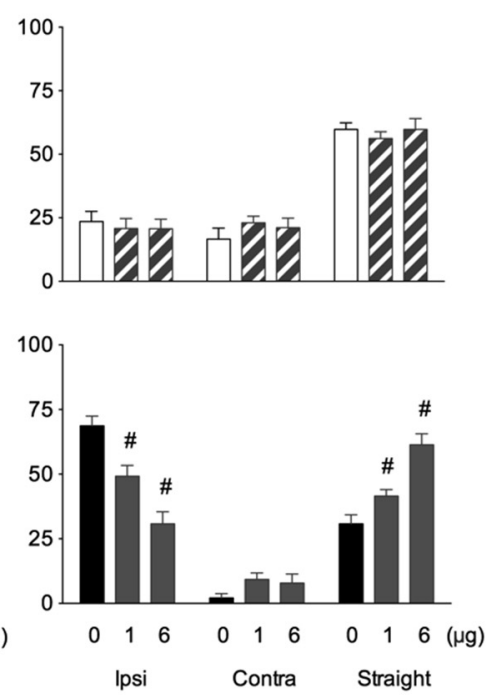

$\square$ Vehicle-sham

Tropicamide-sham
Vehicle-6-OHDA

Tropicamide-6-OHDA
Figure 4. Dorsal striatal M1 and M4 mAChR blockade alleviates parkinsonian-like motor deficits. $\boldsymbol{A}$, Schematic coronal sections from the stereotaxic mouse atlas (Paxinos and Franklin, 2001) (left) and cresyl violet staining (right) at different anteriority levels (from +1.10 to $+0.86 \mathrm{~mm}$ related to bregma) showing the trace of cannula implantation and injector needle placement in the dorsal striatum for M1 and M4 mAChR antagonist injections. Scale bar, $1 \mathrm{~mm}$. $\boldsymbol{B}$, Effects of intrastriatal injection of telenzepine $(0.75$ and $7.5 \mu \mathrm{g}$, i.s.) in the cylinder $(\boldsymbol{B} 1)$ and cross maze $(\boldsymbol{B} 2)$ tests. Each sham $(n=7)$ and 6-OHDA $(n=9)$ group received 3 injections (vehicle or telenzepine 0.75 and $7.5 \mu \mathrm{g}$ ). Data are reported as mean \pm SEM. Tukey's test after significant two-way repeated-measures ANOVA: ${ }^{*} p<0.01$ versus vehicle-sham group; $\# p<0.01$ versus vehicle-6-0HDA. C, Effects of intrastriatal injection of tropicamide (1 and $6 \mu$ g, i.s.) in the cylinder (C1) and cross maze (C2) tests. Each sham $(n=6)$ and 6-0HDA $(n=9)$ group received 3 injections (vehicle or tropicamide 1 and $6 \mu \mathrm{g}$ ). Data are reported as mean \pm SEM. Tukey's test after significant two-way repeated-measures ANOVA: * $p<0.01$ versus vehicle-sham group; $\# p<0.05$ versus vehicle-6-0HDA.

the cylinder (Fig. 5B1; $F_{(2,42)}=27.38, p<0.0001$; Tukey's test, $p=0.9810(0.1 \mu \mathrm{g})$ and $p=0.9834(1 \mu \mathrm{g})$ for sham; $p=0.2386$ $(0.1 \mu \mathrm{g})$ and $p<0.0001(1 \mu \mathrm{g})$ for $6-O H D A]$. Tropicamide had no effect on the sham group in the cross maze (Fig. $5 B 2 ; F_{(4,66)}=$ $2.379, p=0.0605)$. At the dose of $1 \mu \mathrm{g}$, tropicamide significantly decreased ipsilateral arm exploration and increased straight ex- 
A

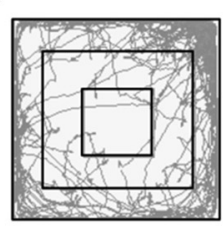

Control

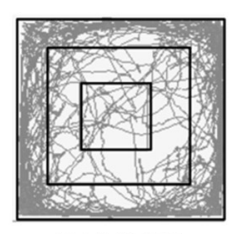

D1-M4-KO
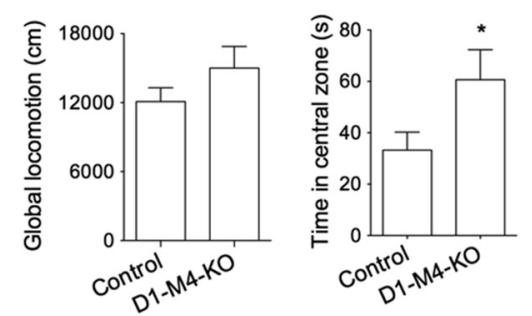

\section{C - D1-M4-KO}

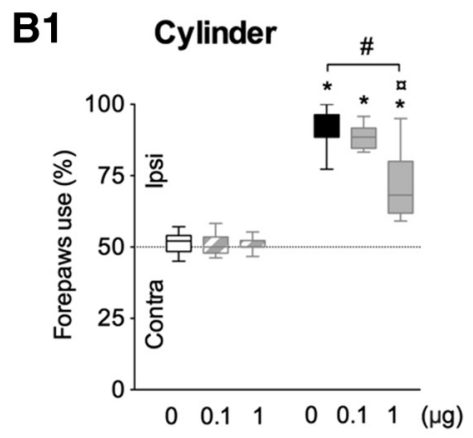

B2
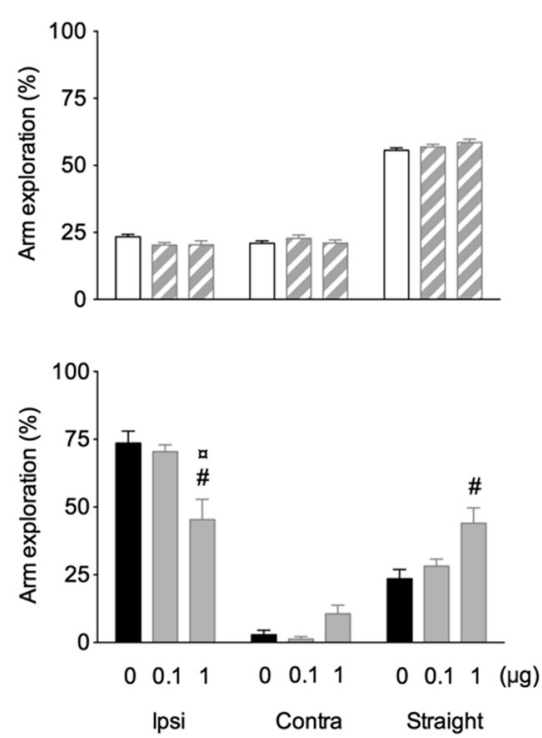

Control (M4 fl/fl) :

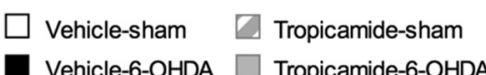

C1

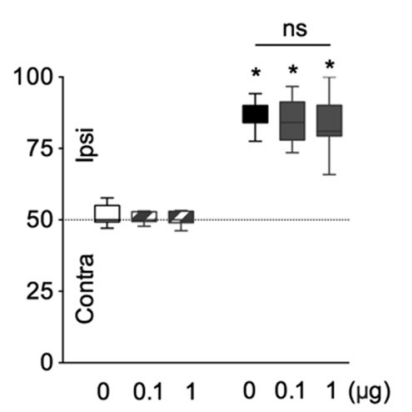

C2
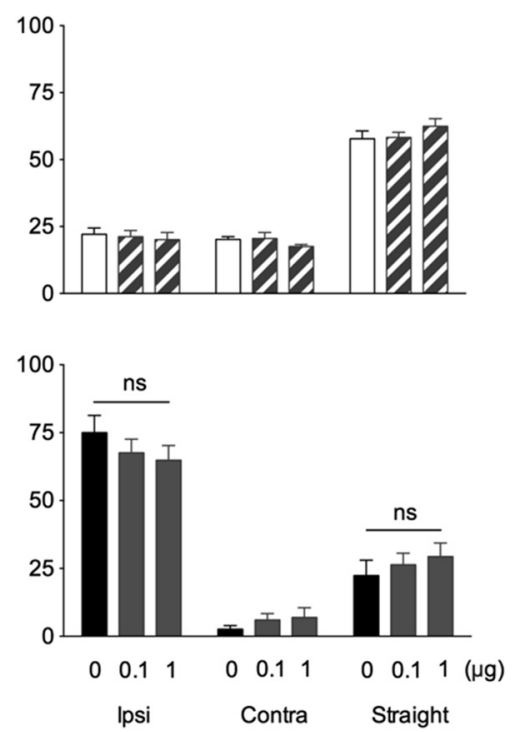

D1-M4-KO :

Vehicle-sham Tropicamide-sham

Vehicle-6-OHDA $\square$ Tropicamide-6-OHDA
Figure 5. Suppression of the beneficial effect of tropicamide on parkinsonian-like motor deficits in transgenic mice lacking M4 mAChRs only in D1-receptor-expressing neurons. $\boldsymbol{A}$, Effects of selective M4 mAChRs deletion only in D1receptor-expressing neurons (D1-M4-KO) on basal locomotor activity (30 $\mathrm{min}$ ) in nonlesioned mice. Representative paths and exploratory behavior of D1-M4-K0 mice $(n=8)$ compared with their control littermates M4 fl/fl $(n=13)$. Quantification showing global locomotion and the time spent in the central zone of the open field. Values are shown as mean \pm SEM. Unpaired Student's $t$ test: ${ }^{*} p<0.05$. B , Effects of intrastriatal injection of tropicamide $(0.1$ and $1 \mu \mathrm{g}$, i.s.) in the cylinder (B1) and cross maze $(\boldsymbol{B} 2)$ tests in control littermates. Each sham $(n=12)$ and 6-0HDA $(n=11)$ group received 3 injections (vehicle or tropicamide 0.1 and $1 \mu \mathrm{g}$ ). Data are reported as mean $\pm \mathrm{SEM}$. Tukey's test after significant two-way repeated-measures ANOVA: * $p<0.01$ versus vehicle-sham group; $\# p<0.01$ versus vehicle-6-0HDA; ap $<0.05$ versus tropicamide $1 \mu \mathrm{g}-6-0$ HDA D1-M4-K0 mice. C, Effects of intrastriatal injection of tropicamide $(0.1$ and $1 \mu \mathrm{g}$, i.s.) in the cylinder (C1) and cross maze $(\mathbf{C} 2)$ test in D1-M4-K0 mice. Each sham $(n=6)$ and 6-0HDA $(n=8)$ group received 3 injections (vehicle or tropicamide 0.1 and $1 \mu \mathrm{g}$ ). Data are reported as mean $\pm \mathrm{SEM}$. Tukey's test after significant two-way repeated-measures ANOVA: ${ }^{*} p<0.01$ versus vehicle-sham group. ploration in 6-OHDA mice $\left[F_{(4,60)}=\right.$ $17.68, p<0.0001$; Tukey's test, $p=0.7793$ $(0.1 \mu \mathrm{g})$ and $p<0,0001(1 \mu \mathrm{g})$ for ipsilateral; $p=0.9366(0.1 \mu \mathrm{g})$ and $p=0.2258$ $(1 \mu \mathrm{g})$ for contralateral; $p=0.5689(0.1$ $\mu \mathrm{g})$ and $p<0.0001(1 \mu \mathrm{g})$ for straight arm exploration)].

Interestingly, tropicamide at the same dose did not reverse the 6-OHDAinduced ipsilateral asymmetry of D1M4-KO mice (Fig. 5C1; $F_{(2,24)}=0.2069$, $p=0.8146)$. In the cross maze, tropicamide had no effect on the sham group (Fig. $5 C 2 ; F_{(4,30)}=1.070, p=0.3888$ ) and did not reverse the 6-OHDA-induced sensorimotor neglect in D1-M4-KO mice (Fig. $4 C 2 ; F_{(4,42)}=2.315, p=0.0730$ ).

Comparisons across D1-M4-KO mice and control littermates showed a main significant interaction between groups and treatment in the cylinder (Fig. 5B1$\left.C 1 ; F_{(6,66)}=14.78, p<0.0001\right)$ and the cross maze (Fig. $5 B 2-C 2 ; F_{(10,102)}=3.822$, $p=0.0002$ ). Tropicamide at a dose of $1 \mu \mathrm{g}$ significantly affected ipsilateral bias between 6-OHDA control and 6-OHDA D1-M4-KO mice in the cylinder (Fig. $5 B 1-C 1$; Tukey's test, $p=0.0012)$ and the cross maze (Fig. 5B2-C2; Tukey's test, $p=$ 0.0225 for ipsilateral arm exploration).

\section{Discussion}

Although our understanding of the contribution of the striatal ChI to basal gangliarelated motor and cognitive functions is growing (Aosaki et al., 2010; Straub et al., 2014), many questions remain unanswered regarding their involvement in the pathophysiology of Parkinson's disease. Here, we show that the selective photoinhibition of striatal ChIs and systemic administration or intrastriatal pharmacological blockade of either M1 or M4 mAChRs in the dorsal striatum alleviate sensorimotor deficits in a unilateral 6-OHDA mice model of Parkinson's disease. We further demonstrate that the beneficial effect of M4 antagonism is lost in mice lacking $\mathrm{M} 4 \mathrm{mAChRs}$ selectively in D1-MSNs. These data provide strong evidence that dysregulated striatal cholinergic transmission via M1/M4 mAChRs, in particular M4 receptors expressed by D1MSNs, is central in motor symptomatology, suggesting promising targets for the development of anti-parkinsonian strategies.

An imbalance between the DA and ACh systems in the dorsal and ventral striatum has long been implicated in the regulation of movement disorders (Pisani et al., 2007; Aosaki et al., 2010; Lester et al., 2010). Selective ventral striatal cholinergic depletion with immunotoxin-mediated cell-targeting techniques results in marked locomotor re- 
sponse to DA stimulation and disruption of sensorimotor-gating processes (Hikida et al., 2001; Laplante et al., 2011). In the dorsal striatum, unilateral immunotoxin-mediated cholinergic depletion produces abnormal contralateral turning behavior that is enhanced by apomorphine (Kaneko et al., 2000). Moreover, viral-targeted ablation of ChIs of the dorsolateral, but not dorsomedial, striatum induces robust stress- and amphetamine-induced stereotyped behavior related to Tourette symptoms (Xu et al., 2015). Interestingly, unlike viral-targeted ablation, the optogenetic photoinhibition of striatal ChIs in control conditions does not modify spontaneous locomotion nor substantia nigra reticulata electrophysiological activity (Maurice et al., 2015).

The validity of optogenetic tools was assessed by recording ChI firing activity in anesthetized eNpHR-RFP mice, which confirmed the inhibition of $\mathrm{ChI}$ action potential firing under eNpHR photoillumination. The reversal of motor improvement is therefore directly linked to the reduction of striatal cholinergic tone in DA-depleted animals and its consequences on MSN membrane excitability, synaptic connectivity, and dendritic morphological changes (Surmeier et al., 2014; Maurice et al., 2015). Recent studies, however, have questioned the antagonistic nature of DA-ACh interaction. Synchronous activation of ChIs was found to elevate striatal DA release via nicotinic receptor activation (Threlfell and Cragg, 2011; Cachope et al., 2012; Threlfell et al., 2012). In addition, stimulation of muscarinic receptors may either reduce or enhance striatal DA release depending on the studies, suggesting that these interactions are more complex than was originally thought (Eskow Jaunarajs et al., 2015).

Nonselective $\mathrm{mAChR}$ antagonists were the first pharmacological treatment for Parkinson's disease and are still used for tremor and gait symptoms. In the present study, we first show that ChIs photoinhibition effect is reproduced by systemic administration of scopolamine, a nonselective mAChRs antagonist. This is consistent with improved motor symptoms of parkinsonian patients treated with benztropine (Duvoisin, 1967) and in recent animal studies (Ding et al., 2011; Xiang et al., 2012). However, their clinical utility has been seriously limited by systemic and central adverse effects caused by nonselective blockade of multiple $\mathrm{mAChRs}$ also located in limbic structures. The recent discovery of drugs that act selectively at the M1 or M4 mAChR subtypes may provide new tools to treat motor symptoms with fewer side effects (Langmead et al., 2008; Lester et al., 2010). In addition, M4 receptors are primarily expressed in the striatum and, at lower levels, in several other brain regions, including cerebral cortex and hippocampus (Gomeza et al., 1999). This may prevent the occurrence of cognitive side effects.

Immunocytochemical studies reveal a predominant expression of M1 and M4 mAChRs, relative to M2 and M3 subtypes, within the striatum (Bonsi et al., 2011). M1 mAChRs are coupled to Gq proteins that activate phospholipase $\mathrm{C}$, resulting in activation of inositol trisphosphatase and diacyl-glycerol, ultimately increasing intracellular calcium (Pisani et al., 2007). Striatal M1 mAChRs are highly expressed postsynaptically in both D1-MSNs and D2-MSNs. Their blockade is thus expected to inhibit the activity of the two output pathways. Here, we demonstrate that the M1 preferential antagonist telenzepine, administered systemically or locally in the dorsolateral striatum, reduces 6-OHDAinduced motor deficits as observed after scopolamine treatment or striatal ChI photoinhibition. Telenzepine is reported to have preferential activity at M1 mAChRs compared with other muscarinic subtypes (Doods et al., 1987) and is four to 10 times more potent than pirenzepine, a widely used M1 mAChR antagonist (Eltze et al., 1985). Interestingly, pirenzepine was also found to inhibit haloperidol-induced catalepsy in rats when centrally injected and was more effective than M2, M3, or M4 antagonists (Erosa-Rivero et al., 2014), supporting the importance of M1 $\mathrm{mAChR}$ subtypes as an interesting anti-parkinsonian drug target. In vitro electrophysiological studies revealed that $\mathrm{ACh}$ has been involved in striatal long-term potentiation (LTP) or long-term depression (LTD) induction. An excessive cholinergic transmission overactivates M1 mAChRs, thus preventing LTD in favor of LTP (Bonsi et al., 2008). Cholinergic receptor antagonists (pirenzepine, trihexyphenidyl) were able to restore a normal expression of LTD. Because the indirect pathway is considered hyperactive in parkinsonian state, whereas the direct pathway is hypoactive, it may be postulated that the beneficial action of telenzepine reported here involves preferential blockade of M1 mAChRs located on D2-MSNs.

Whereas actions of M1 mAChRs have been explored extensively, much less is known about M4 mAChRs that are highly expressed in the striatum (Langmead et al., 2008; Chapman et al., 2011). Consistent with the beneficial action of M4 mAChR blockade measured on sensorimotor deficits, tropicamide has been reported to suppress tremulous jaw movements in a rodent model of parkinsonian tremor (Betz et al., 2007). Moreover, scopolamine reversed haloperidol-induced catalepsy in wild-type mice, but had only a weak effect in M4 knock-out mice, thus highlighting a predominant role of these receptors in these effects (Karasawa et al., 2003). M4 mAChRs activate Gi/o proteins and are located in the striatum presynaptically on striatal ChI terminals, where they function as cholinergic autoreceptors inhibiting ACh release, along with M2 mAChRs (Kreitzer, 2009), and postsynaptically on D1-MSNs, where their activation results, among other mechanisms, in Cav2 channel inhibition and therefore shapes the spiking of MSNs (Santiago and Potter, 2001; Pisani et al., 2007). The loss of striatal DA has been reported to attenuate M4 autoreceptor signaling in ChIs, which might be a main factor in elevated striatal ACh release after DA depletion (Ding et al., 2006). Such adaptation is likely to limit the outcomes of M4 autoreceptor antagonism, which should otherwise have proparkinsonian rather than anti-parkinsonian action. After DA depletion, tropicamide may thus act preferentially on postsynaptic M4 receptors expressed in D1-MSNs, accounting for the symptomatic relief found there. We validated our hypothesis by showing that the alleviation of motor deficits by tropicamide is lost in mutant mice that lack M4 mAChRs in D1 DA-receptorexpressing cells (Jeon et al., 2010). These data indicate that activation of M4 mAChRs in D1-MSNs is a key component of ChIs involvement in parkinsonian symptomatology and are consistent with our recent work showing predominant outcomes of $\mathrm{ChI}$ inhibition on D1-MSNs versus D2-MSNs in 6-OHDA-lesioned mice, both in terms of excitability and implication in cortical information processing through the basal ganglia (Maurice et al., 2015). M4 mAChR subtypes exert an inhibitory control on D1receptor-mediated locomotor stimulation (Gomeza et al., 1999). Their stimulation potently counteracts the activation of adenylyl cyclase induced by a selective D1 receptor agonist in membranes of the ventral striatum, strongly suggesting that the DA-ACh balance takes place in D1-MSNs (Onali and Olianas, 2002). Here, D1-M4-KO mice exhibit enhanced basal locomotor activity and anxiolytic phenotype consistent with an increase of DA efflux in the ventral striatum associated with an hyperlocomotor response to psychostimulants observed previously in these mutant mice (Jeon et al., 2010; Dencker et al., 2011). One could expect reduced sensorimotor symptoms in D1-M4-KO mice if similar adaptive 
mechanisms occur in the dorsal striatum, but not in our conditions of severe dopamine denervation.

The complexity of D1 and M4 mAChR interactions in the treatment of L-DOPA-induced dyskinesia (LIDs) has also been highlighted recently. In vitro, the actions of the M4 and D1 receptors may be additive to produce a robust enhancement of D1-MSN excitability or, conversely, oppose each other depending on the order of their activation (Hernández-Flores et al., 2015). Such an antagonistic interaction of M4 and D1 receptors may explain a recent work showing that increasing cholinergic signaling with an M4 mAChR-positive allosteric modulator attenuates LIDs by promoting D1-MSN LTD in mice (Shen et al., 2015). In contrast, selective ablation of striatal ChI or mAChR blockade reduces LIDs (Ding et al., 2011; Won et al., 2014; Bordia et al., 2016), supporting the hypothesis that blockade rather than enhancement of cholinergic activity at M4 mAChRs may be relevant to alleviating LIDs and parkinsonian motor symptoms.

In the present study, administration of either muscarinic antagonists or L-DOPA alleviated sensorimotor deficits in unilateral 6-OHDA-lesioned mice. However, L-DOPA also produces contralateral bias and sometimes dyskinesia, which may indicate the limits of L-DOPA treatment for restoring normal function in our model of extensive dopamine denervation.

In summary, striatal ChI photoinhibition and M1 or M4 mAChR blockade alleviate parkinsonian-like motor symptoms in 6-OHDA-lesioned mice. M1 mAChR blockade may act preferentially on the indirect pathway, whereas M4 mAChR blockade involves the direct pathway. Therefore, the development of combined M1/M4 mAChR blockers appears to be a particularly attractive goal for reducing striatal cholinergic tone to alleviate the motor symptoms of Parkinson's disease while limiting side effects.

\section{References}

Albin RL, Young AB, Penney JB (1989) The functional anatomy of basal ganglia disorders. Trends Neurosci 12:366-375. CrossRef Medline

Aliane V, Pérez S, Bohren Y, Deniau JM, Kemel M-L (2011) Key role of striatal cholinergic interneurons in processes leading to arrest of motor stereotypies. Brain 134:110-118. CrossRef Medline

Aosaki T, Miura M, Suzuki T, Nishimura K, Masuda M (2010) Acetylcholine-dopamine balance hypothesis in the striatum: an update. Geriatr Gerontol Int 10:S148-S157. CrossRef Medline

Betz AJ, McLaughlin PJ, Burgos M, Weber SM, Salamone JD (2007) The muscarinic receptor antagonist tropicamide suppresses tremulous jaw movements in a rodent model of parkinsonian tremor: possible role of M4 receptors. Psychopharmacology 194:347-359. CrossRef Medline

Bonsi P, Martella G, Cuomo D, Platania P, Sciamanna G, Bernardi G, Wess J, Pisani A (2008) Loss of muscarinic autoreceptor function impairs longterm depression but not long-term potentiation in the striatum. J Neurosci 28:6258-6263. CrossRef Medline

Bonsi P, Cuomo D, Martella G, Madeo G, Schirinzi T, Puglisi F, Ponterio G, Pisani A (2011) Centrality of striatal cholinergic transmission in basal ganglia function. Front Neuroanat 5:6. CrossRef Medline

Bordia T, Perez XA, Heiss JE, Zhang D, Quik M (2016) Optogenetic activation of striatal cholinergic interneurons regulates L-dopa-induced dyskinesias. Neurobiol Dis 91:47-58. CrossRef Medline

Cachope R, Mateo Y, Mathur BN, Irving J, Wang HL, Morales M, Lovinger DM, Cheer JF (2012) Selective activation of cholinergic interneurons enhances accumbal phasic dopamine release: setting the tone for reward processing. Cell Rep 2:33-41. CrossRef Medline

Calabresi P, Centonze D, Gubellini P, Pisani A, Bernardi G (2000) Acetylcholine-mediated modulation of striatal function. Trends Neurosci 23:120-126. CrossRef Medline

Calabresi P, Picconi B, Tozzi A, Ghiglieri V, Di Filippo M (2014) Direct and indirect pathways of basal ganglia: a critical reappraisal. Nat Neurosci 17:1022-1030. CrossRef Medline

Chapman KL, Vaswani D, Hendry N, Langmead CJ, Kew JN, Watson JM
(2011) The muscarinic M(4) receptor is the functionally predominant subtype in rat and mouse striatum as demonstrated using [(35)S] GTP $\gamma \mathrm{S}$ binding. Eur J Pharmacol 652:1-6. CrossRef Medline

Dencker D, Wörtwein G, Weikop P, Jeon J, Thomsen M, Sager TN, Mørk A, Woldbye DP, Wess J, Fink-Jensen A (2011) Involvement of a subpopulation of neuronal $\mathrm{m} 4$ muscarinic acetylcholine receptors in the antipsychotic-like effects of the M1/M4 preferring muscarinic receptor agonist xanomeline. J Neurosci 31:5905-5908. CrossRef Medline

Di Chiara G, Morelli M, Consolo S (1994) Modulatory functions of neurotransmitters in the striatum: ACh/dopamine/NMDA interactions. Trends Neurosci 17:228-233. CrossRef Medline

Ding J, Guzman JN, Tkatch T, Chen S, Goldberg JA, Ebert PJ, Levitt P, Wilson CJ, Hamm HE, Surmeier DJ (2006) RGS4-dependent attenuation of M4 autoreceptor function in striatal cholinergic interneurons following dopamine depletion. Nat Neurosci 9:832-842. CrossRef Medline

Ding Y, Won L, Britt JP, Lim SA, McGehee DS, Kang UJ (2011) Enhanced striatal cholinergic neuronal activity mediates L-DOPA-induced dyskinesia in parkinsonian mice. Proc Natl Acad Sci U S A 108:840-845. CrossRef Medline

Doods HN, Mathy MJ, Davidesko D, van Charldorp KJ, de Jonge A, van Zwieten PA (1987) Selectivity of muscarinic antagonists in radioligand and in vivo experiments for the putative M1, M2 and M3 receptors. J Pharmacol Exp Ther 242:257-262. Medline

Duvoisin RC (1967) Cholinergic-anticholinergic antagonism in parkinsonism. Arch Neurol 17:124-136. CrossRef Medline

Eltze M, Gönne S, Riedel R, Schlotke B, Schudt C, Simon WA (1985) Pharmacological evidence for selective inhibition of gastric acid secretion by telenzepine, a new antimuscarinic drug. Eur J Pharmacol 112:211-224. CrossRef Medline

Erosa-Rivero HB, Bata-García JL, Alvarez-Cervera FJ, Heredia-López FJ, Góngora-Alfaro JL (2014) The potency and efficacy of anticholinergics to inhibit haloperidol-induced catalepsy in rats correlates with their rank order of affinities for the muscarinic receptor subtypes. Neuropharmacology 81:176-187. CrossRef Medline

Eskow Jaunarajs KL, Bonsi P, Chesselet MF, Standaert DG, Pisani A (2015) Striatal cholinergic dysfunction as a unifying theme in the pathophysiology of dystonia. Prog Neurobiol 127-128:91-107. CrossRef Medline

Francardo V, Recchia A, Popovic N, Andersson D, Nissbrandt H, Cenci MA (2011) Impact of the lesion procedure on the profiles of motor impairment and molecular responsiveness to L-DOPA in the 6-hydroxydopamine mouse model of Parkinson's disease. Neurobiol Dis 42:327340. CrossRef Medline

Gomeza J, Zhang L, Kostenis E, Felder C, Bymaster F, Brodkin J, Shannon H, Xia B, Deng C, Wess J (1999) Enhancement of D1 dopamine receptormediated locomotor stimulation in $\mathrm{M}(4)$ muscarinic acetylcholine receptor knockout mice. Proc Natl Acad Sci U S A 96:10483-10488. CrossRef Medline

Hernández-Flores T, Hernández-González $\mathrm{O}$, Pérez-Ramírez MB, LaraGonzález E, Arias-García MA, Duhne M, Pérez-Burgos A, Prieto GA, Figueroa A, Galarraga E, Bargas J (2015) Modulation of direct pathway striatal projection neurons by muscarinic $\mathrm{M}_{4}$-type receptors. Neuropharmacology 89:232-244. CrossRef Medline

Hikida T, Kaneko S, Isobe T, Kitabatake Y, Watanabe D, Pastan I, Nakanishi $S$ (2001) Increased sensitivity to cocaine by cholinergic cell ablation in nucleus accumbens. Proc Natl Acad Sci U S A 98:13351-13354. CrossRef Medline

Jeon J, Dencker D, Wörtwein G, Woldbye DP, Cui Y, Davis AA, Levey AI, Schütz G, Sager TN, Mørk A, Li C, Deng CX, Fink-Jensen A, Wess J (2010) A subpopulation of neuronal M4 muscarinic acetylcholine receptors plays a critical role in modulating dopamine-dependent behaviors. J Neurosci 30:2396-2405. CrossRef Medline

Kaneko S, Hikida T, Watanabe D, Ichinose H, Nagatsu T, Kreitman RJ, Pastan I, Nakanishi S (2000) Synaptic integration mediated by striatal cholinergic interneurons in basal ganglia function. Science 289:633-637. CrossRef Medline

Karasawa H, Taketo MM, Matsui M (2003) Loss of anti-cataleptic effect of scopolamine in mice lacking muscarinic acetylcholine receptor subtype 4 . Eur J Pharmacol 468:15-19. CrossRef Medline

Kreitzer AC (2009) Physiology and pharmacology of striatal neurons. Neuroscience 32:127-147. CrossRef Medline

Langmead CJ, Watson J, Reavill C (2008) Muscarinic acetylcholine receptors as CNS drug targets. Pharmacol Ther 117:232-243. CrossRef Medline 
Laplante F, Lappi DA, Sullivan RM (2011) Cholinergic depletion in the nucleus accumbens: effects on amphetamine response and sensorimotor gating. Prog Neuropsychopharmacol Biol Psychiatry 35:501-509. CrossRef Medline

Lees A (2005) Alternatives to levodopa in the initial treatment of early Parkinson's disease. Drugs Aging 22:731-740. CrossRef Medline

Lester DB, Rogers TD, Blaha CD (2010) Acetylcholine-dopamine interactions in the pathophysiology and treatment of CNS disorders. CNS Neurosci Ther 16:137-162. CrossRef Medline

Maurice N, Liberge M, Jaouen F, Ztaou S, Hanini M, Camon J, Deisseroth K, Amalric M, Kerkerian-Le Goff L, Beurrier C (2015) Striatal cholinergic interneurons control motor behavior and basal ganglia function in experimental Parkinsonism. Cell Rep 13:657-666. CrossRef Medline

Obeso JA, Rodríguez-Oroz MC, Rodríguez M, Lanciego JL, Artieda J, Gonzalo N, Olanow CW (2000) Pathophysiology of the basal ganglia in Parkinson's disease. Trends Neurosci 23:S8 -S19. CrossRef Medline

Onali P, Olianas MC (2002) Muscarinic M4 receptor inhibition of dopamine D1-like receptor signalling in rat nucleus accumbens. Eur J Pharmacol 448:105-111. CrossRef Medline

Parker PR, Lalive AL, Kreitzer AC (2016) Pathway-specific remodeling of thalamostriatal synapses in parkinsonian mice. Neuron 89:734-740. CrossRef Medline

Paxinos G, Franklin KBJ (2001) The mouse brain in stereotaxic coordinates, Ed 2. San Diego: Academic.

Pisani A, Bernardi G, Ding J, Surmeier DJ (2007) Re-emergence of striatal cholinergic interneurons in movement disorders. Trends Neurosci 30: 545-553. CrossRef Medline

Santiago MP, Potter LT (2001) Biotinylated m4-toxin demonstrates more M4 muscarinic receptor protein on direct than indirect striatal projection neurons. Brain Res 894:12-20. CrossRef Medline

Shen W, Plotkin JL, Francardo V, Ko WK, Xie Z, Li Q, Fieblinger T, Wess J, Neubig RR, Lindsley CW, Conn PJ, Greengard P, Bezard E, Cenci MA, Surmeier DJ (2015) M4 muscarinic receptor signaling ameliorates striatal plasticity deficits in models of L-DOPA-induced dyskinesia. Neuron 88:762-773. CrossRef Medline

Silberberg G, Bolam JP (2015) Local and afferent synaptic pathways in the striatal microcircuitry. Curr Opin Neurobiol 33:182-187. CrossRef Medline

Straub C, Tritsch NX, Hagan NA, Gu C, Sabatini BL (2014) Multiphasic modulation of cholinergic interneurons by nigrostriatal afferents. J Neurosci 34:8557-8569. CrossRef Medline
Surmeier DJ, Graves SM, Shen W (2014) Dopaminergic modulation of striatal networks in health and Parkinson's disease. Curr Opin Neurobiol 29:109-117. CrossRef Medline

Tecuapetla F, Matias S, Dugue GP, Mainen ZF, Costa RM (2014) Balanced activity in basal ganglia projection pathways is critical for contraversive movements. Nat Commun 5:4315. CrossRef Medline

Tepper JM, Bolam JP (2004) Functional diversity and specificity of neostriatal interneurons. Curr Opin Neurobiol 14:685-692. CrossRef Medline

Threlfell S, Cragg SJ (2011) Dopamine signaling in dorsal versus ventral striatum: the dynamic role of cholinergic interneurons. Front Syst Neurosci 5:11. CrossRef Medline

Threlfell S, Lalic T, Platt NJ, Jennings KA, Deisseroth K, Cragg SJ (2012) Striatal dopamine release is triggered by synchronized activity in cholinergic interneurons. Neuron 75:58-64. CrossRef Medline

Tritsch NX, Carter AG (2016) Parkinson's disease: a thalamostriatal rebalancing act? Neuron 89:675-677. CrossRef Medline

Wess J, Eglen RM, Gautam D (2007) Muscarinic acetylcholine receptors: mutant mice provide new insights for drug development. Nat Rev Drug Discov 6:721-733. CrossRef Medline

Won L, Ding Y, Singh P, Kang UJ (2014) Striatal cholinergic cell ablation attenuates L-DOPA induced dyskinesia in Parkinsonian mice. J Neurosci 34:3090-3094. CrossRef Medline

Xiang Z, Thompson AD, Jones CK, Lindsley CW, Conn PJ (2012) Roles of the $\mathrm{m} 1$ muscarinic acetylcholine receptor subtype in the regulation of Basal Ganglia function and implications for the treatment of Parkinson's disease. J Pharmacol Exp Ther 340:595-603. CrossRef Medline

Xu M, Kobets A, Du JC, Lennington J, Li L, Banasr M, Duman RS, Vaccarino FM, DiLeone RJ, Pittenger C (2015) Targeted ablation of cholinergic interneurons in the dorsolateral striatum produces behavioral manifestations of Tourette syndrome. Proc Natl Acad Sci U S A 112:893-898. CrossRef Medline

Zhang W, Basile AS, Gomeza J, Volpicelli LA, Levey AI, Wess J (2002) Characterization of central inhibitory muscarinic autoreceptors by the use of muscarinic acetylcholine receptor knock-out mice. J Neurosci 22: 1709-1717. Medline

Zhou FM, Wilson C, Dani JA (2003) Muscarinic and nicotinic cholinergic mechanisms in the mesostriatal dopamine systems. Neuroscientist 9: 23-36. CrossRef Medline 